\title{
$O$ cuidado prestado às famílias no centro de atenção psicossocial: percepções dos
}

\section{profissionais}

\author{
The care provided to families in the psychosocial care center: perceptions of professionals \\ La atención prestada a las familias en el centro de atención psicosocial: percepciones de los \\ profesionales
}

Recebido: 12/08/2021 | Revisado: 22/08/2021 | Aceito: 24/08/2021 | Publicado: 25/08/2021

\author{
Priscila de Oliveira Maia \\ ORCID: https://orcid.org/0000-0001-7978-2647 \\ Universidade de São Paulo, Brasil \\ E-mail: prii.maiia@gmail.com \\ Jussara Carvalho dos Santos \\ ORCID: https://orcid.org/0000-0002-7008-2756 \\ Universidade de São Paulo, Brasil \\ E-mail: jusantos@usp.br
}

\begin{abstract}
Resumo
O objetivo deste estudo é identificar as ações dos profissionais de saúde acerca do cuidado prestado aos familiares de usuários de um Centro de Atenção Psicossocial Adulto III. Método: Pesquisa qualitativa do tipo descritivo e exploratório. A coleta de dados foi realizada por meio de entrevista gravada, guiada por questionário semiestruturado, aplicada a 28 profissionais de um CAPSIII do município de São Paulo. Os dados foram processados por software. Resultados: A partir do corpus analisado emergiram seis classes que tratam sobre o conceito de família, a importância do cuidado e do vínculo, além das ações ofertadas pelo serviço para promoção do cuidado com o familiar. Conclusão: Profissionais evidenciam a importância de estarem próximos dos familiares, o que acarreta melhora no tratamento ao usuário. Dentre as ações ofertadas para o cuidado da família são: grupo de família e visitas domiciliares. Incluir o resumo.
\end{abstract}

Palavras-chave: Saúde mental; Serviços de saúde mental; Família; Relações profissional-família; Enfermagem.

\begin{abstract}
The aim of this study is to identify the actions of health professionals regarding the care provided to family members of users of an Adult Psychosocial Care Center III. Method: Qualitative descriptive and exploratory research. Data collection was performed through recorded interviews, guided by a semi-structured questionnaire, applied to 28 professionals from a CAPSIII in the city of São Paulo. Data were processed by software. Results: From the analyzed corpus, six classes emerged that deal with the concept of family, the importance of care and bonding, in addition to the actions offered by the service to promote care for the family member. Conclusion: Professionals highlight the importance of being close to family members, which improves the treatment of users. Among the actions offered for family care are: family groups and home visits.
\end{abstract}

Keywords: Mental health; Mental health services; Family; Professional-family relations; Nursing.

\section{Resumen}

El objetivo de este estudio es identificar las acciones de los profesionales de la salud en la atención brindada a los familiares de los usuarios de un Centro de Atención Psicosocial de Adultos III. Método: Investigación cualitativa descriptiva y exploratoria. La recolección de datos se realizó a través de entrevistas grabadas, guiadas por un cuestionario semiestructurado, aplicado a 28 profesionales de un CAPSIII en la ciudad de São Paulo. Los datos fueron procesados por software. Resultados: Del corpus analizado surgieron seis clases que abordan el concepto de familia, la importancia del cuidado y la vinculación, además de las acciones que ofrece el servicio para promover el cuidado del familiar. Conclusión: Los profesionales destacan la importancia de estar cerca de los familiares, lo que mejora el trato a los usuarios. Entre las acciones que se ofrecen para el cuidado familiar se encuentran: grupos familiares y visitas domiciliarias.

Palabras clave: Salud mental; Servicios de salud mental; Familia; Relaciones profesionales-familiares; Enfermería. 


\section{Introdução}

A implantação da política nacional de saúde mental, norteada pela reforma psiquiátrica, é orientada pelo paradigma da atenção e reabilitação psicossocial, além de se pautar no marco jurídico da lei no 10.216 de 2001. O modelo de atenção psicossocial visa a desinstitucionalização, a inclusão social, o cuidado de forma integral e a inserção da família como parceira no tratamento (Reis, Dahl, Barbosa, Teixeira, \& Delgado, 2016; Carvalho et al, 2016; Jafelice, Ziliotto, \& Marcolan, 2020). Este modelo se expressa na Rede de Atenção Psicossocial que se dispõe a articular ações e serviços de diferentes complexidades no âmbito do Sistema Único de Saúde (SUS) para garantia do cuidado em liberdade, com ênfase no território/comunidade, no processo da Reforma Psiquiátrica ainda em curso no país como descrito na Portaria $\mathrm{n}^{\mathrm{o}} 3.088$ de 2011.

Os Centros de Atenção Psicossocial (CAPS), serviço comunitário de saúde, integram a rede de serviços estratégicos na superação do modelo manicomial. Na atenção psicossocial, a família passou a ser vista como potência para o cuidado, pois, além de ser a primeira referência na vida do indivíduo, ela também propicia construção cultural e social do indivíduo e, consequentemente, da sociedade a qual pertence. Dessa forma, a relação familiar também pode contribuir com a sensação de segurança e de apoio entre os seus membros (Randemark \& Barros, 2014; Gomes \& Santos, 2016).

Além do cuidado compartilhado, os CAPS precisam olhar com atenção para o sofrimento gerado pela sobrecarga do familiar em decorrência do convívio com o sujeito com sofrimento mental ${ }^{(1)}$. Sendo assim, a partir do vínculo estabelecido com a equipe de saúde, a inserção da família no tratamento pode vir a diminuir as internações, amenizar os conflitos e melhorar a qualidade de vida de todos no domicílio (Oliveira et al, 2016; Lima, Aguiar \& Sousa, 2015).

No CAPS, o acompanhamento da família ofertado através de ações como atendimentos individuais e grupo de família é um dever importante previsto na Portaria n 336/GM/MS de 2002. No entanto, é preciso investir na construção de estratégias de educação em saúde, de habilidades para o manejo diário e nos momentos de crise, junto a participação da família, a fim de promover uma melhor interação desta com o usuário (Delgado, 2014). Dessa forma, os investimentos na rede familiar também afetam a rede social do sujeito, beneficiando a reabilitação psicossocial e a ampliação dos espaços de trocas afetivas e materiais (Saraceno, 2001).

Neste sentido, o pressuposto é de que as ações são pontuais e focadas nas necessidades do usuário do serviço de saúde. Além disso, é importante considerar que o desmonte da política de saúde pode interferir no reforço desse pressuposto, redirecionando o modelo de atenção em saúde mental para uma lógica manicomial, a qual tende a isolar a família e a não trabalhar com suas necessidades na relação com a pessoa em sofrimento. Assim, surgem as seguintes questões norteadoras: Quais são as ações da equipe multiprofissional em relação ao cuidado prestado à família de usuários do CAPS adulto III? Quais são os espaços de acolhimento da família?

O presente estudo, que tem como base a perspectiva psicossocial, é indispensável para se compreender, avançar e efetivar o processo da Reforma Psiquiátrica brasileira antimanicomial, pois revisita o fazer mudanças e o construir novos processos de cuidado dentro de uma clínica ampliada, não reducionista focada em familiares de pessoas em sofrimento mental.

Diante desse panorama, o presente estudo tem como objetivo identificar as ações dos profissionais de saúde acerca do cuidado prestado aos familiares de usuários de um CAPS adulto III.

\section{Metodologia}

Estudo qualitativo, do tipo descritivo e exploratório, pela característica de observar, classificar e descrever fenômenos (Minayo, 2010; Estrela, 2018). Participaram 28 profissionais em um CAPS Adulto III da Zona Oeste do município de São Paulo. Os critérios de inclusão foram: possuir nível técnico e/ou superior, estar há, pelo menos, três meses atuando na unidade de trabalho atual. Foram excluídos do estudo os profissionais que estavam em férias ou licença saúde no período programado 
para as entrevistas e aqueles que atuavam na farmácia, setor administrativo e gestão. Estes últimos, excluídos por não possuírem definidos em suas atribuições o cuidado direto ao usuário e familiar do serviço de saúde de acordo com a descrição do cargo municipal.

A coleta de dados ocorreu, de setembro a dezembro de 2018, por meio de entrevistas realizadas em uma sala silenciosa e sem interferência externa dentro do próprio CAPS, durante o período de trabalho dos profissionais participantes. Neste local, foi aplicado um questionário semiestruturado com as seguintes questões guias: Como você define o conceito de família? O que você entende sobre cuidar e acolher a família do usuário? Quais são as ações promovidas pelo serviço para o cuidado dos familiares? Quais são as ações que você faz voltadas para o cuidado da família? Esse questionário foi aplicado em uma sala privativa, sem interrupções, disponibilizada pelo profissional em seu ambiente de trabalho, somente após a assinatura de cada participante do Termo de Consentimento Livre e Esclarecido (TCLE). Todas as entrevistas foram gravadas com duração média de sete minutos, transcritas na íntegra e identificadas através da codificação com a letra $\mathrm{P}$ seguida do número referente ao profissional entrevistado, de forma sequencial. O material das entrevistas ficou guardado sob posse e acesso das autoras.

Após a etapa de transcrição das entrevistas, o material foi agrupado em um único corpus de análise e processado por meio do software Analyse Lexicale par Context d'un Ensemble de Segments de Texte - Versão 0.7 alpha 2 (também conhecido como IRAMUTEQ), que é desenvolvido na linguagem Python e ancorado no software estatístico R.

Para a análise textual da pesquisa, foi utilizada Classificação Hierárquica Descendente (CHD) e a nuvem de palavras que agrupa as palavras organizando-as de acordo com a sua frequência. $\mathrm{Na} \mathrm{CHD}$, a partir do corpus, foi realizado o dimensionamento dos Segmentos de Texto (ST), classificados em função dos vocabulários de maior frequência e de valores de Qui-Quadrado ( $\left.X^{2}\right)$ mais elevado na classe (Lowen, Peres, Crozeta, Bernardino, \& Beck, 2015). Os ST foram repartidos em função da frequência das formas reduzidas e possuem em média três linhas (Souza, Wall, Thuler, Lowen, \& Peres, 2018).

Com base no corpus original, a associação dos ST permitiu o agrupamento das palavras estatisticamente significativas e a análise qualitativa dos dados. Sendo assim, os ST que compõem as classes, são obtidos a partir do conjunto de cada entrevista, denominada corpus, e que apresentam vocabulário semelhante entre si e diferentes dos ST das outras classes (Souza et al, 2018).

Os dados foram analisados de acordo com a baliza teórica adotada neste estudo - conceito de família (Mioto, 1998) e com a categoria analítica o conceito de Reabilitação Psicossocial de Benedeto Saraceno. Essa última se define pelo conjunto de estratégias orientadas a aumentar as oportunidades de trocas de recursos e afetos, a partir da reconstrução do exercício pleno de cidadania do sujeito (Saraceno, 2001).

Este estudo foi aprovado no ano de 2018 pelos Comitês de Ética e Pesquisa da Escola de Enfermagem da Universidade de São Paulo sob o parecer no 2.830.940 em conformidade com a Resolução do Conselho Nacional de Saúde 466/2012. A coleta de dados foi realizada somente após a assinatura de cada participante do Termo de Consentimento Livre e Esclarecido (TCLE).

\section{Resultados}

Dentre 28 profissionais participantes, 21 (75\%) por pessoas do sexo feminino, com idade média de 36 anos e nivel educacional correspondente ao superior completo 21(75\%). Dentre as profissões, compõem-se por 8 auxiliares de enfermagem (22,4\%), 6 enfermeiros (21,4\%), 5 terapeutas ocupacionais (17,8\%), 4 psicólogos (14,2\%), 2 médicos (7,1\%), 2 técnicos de enfermagem $(7,1 \%)$ e 1 assistente social (3,5\%). Dos participantes do estudo, $16(57,1 \%)$ são graduados entre 5 meses a 9 anos, e $12(42,8 \%)$ a mais de 10 anos. Quanto à formação complementar dos profissionais, 10 (35,7\%) possuem título de especialização em saúde mental, 7 (25\%) em outras áreas e 11 (39,2\%) não possuem formação complementar. Quanto ao 
tempo de trabalho atual, 23 profissionais $(82,1 \%)$ atuam de 2 a 10 anos, e 5 (17,8\%) há menos de 1 ano. No grupo de família, apenas quatro dos entrevistados participavam ativamente.

Pelo método da nuvem de palavras (Figura 1), que analisa e agrupa de acordo com a frequência, observa-se que a palavra 'família' apresentou maior número de aparição no corpus (169), seguida do termo ‘usuário' (123), 'grupo de família' (88), 'cuidado' (59) e 'visitas domiciliares'(40).

Figura 1 - Nuvem de palavras gerada pelo software Iramuteq - São Paulo, 2019.

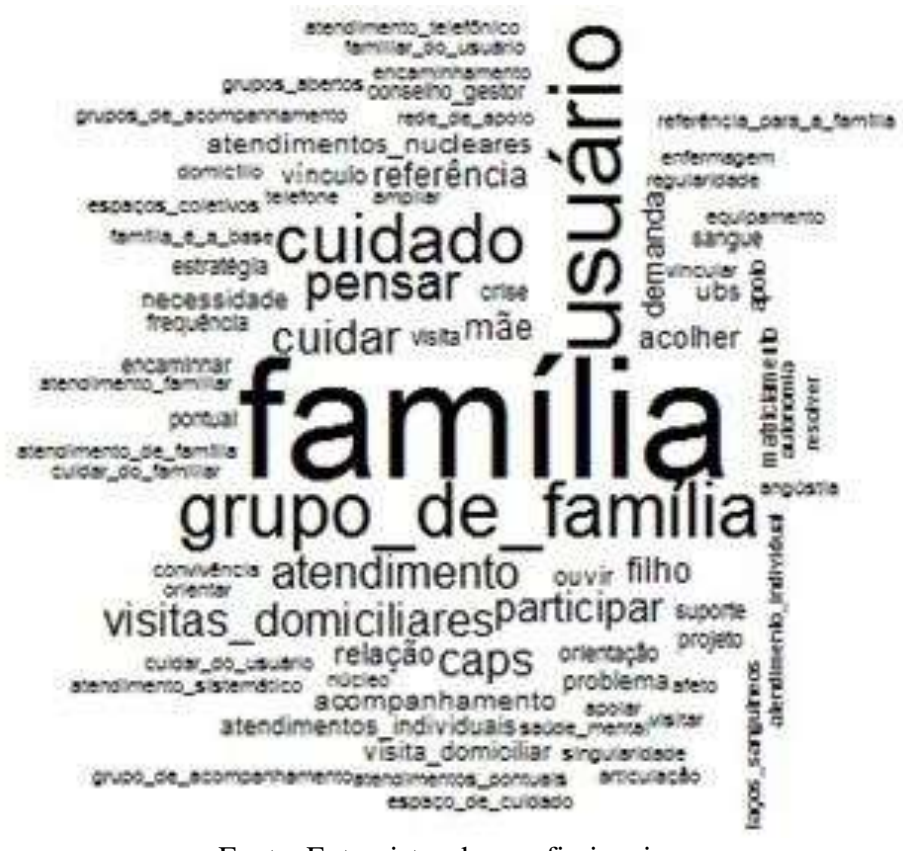

Fonte: Entrevistas dos profissionais.

O processamento do corpus foi realizado em 26 segundos e foram classificados 488 ST, dos quais 442 foram aproveitados, ou seja, $90.57 \%$ do total do corpus. Considera-se um bom aproveitamento de ST o índice de $75 \%$ ou mais. O programa utiliza o teste $\mathrm{X}^{2}$ que revela a força associativa entre as palavras e sua respectiva classe. Essa força associativa é analisada quando o teste for maior que 3,84, representado por $\mathrm{p}<0,0001$. Todas as palavras selecionadas possuíam $\mathrm{p}<0,0001$, indicando associação significativa. O menor valor de $X^{2}$ representa uma menor relação entre as variáveis (Souza et al, 2018).

A CHD após ser processada cria dendograma que apresenta as classes, demonstrando a ligação e associação entre elas. Para a análise textual e a apresentação das classes referentes ao conceito de família e as ações voltadas para esse público, o corpus, constituído por 28 entrevistas, gerou seis classes de ST diferentes entre si.

O corpus foi dividido em dois subcorpus. No primeiro subcorpus houve duas subdivisões que englobou a classe 3, com $76 \mathrm{ST}$, e a classe 4, com $70 \mathrm{ST}$, sendo $17,19 \%$ referente à classe 3 e 15,84\% à classe 4 do total das ST. Em relação à outra subdivisão, gerou a classe 5, com 53 ST, e a classe 6, com 108 ST. Respectivamente 11,99\% e 24,43\% relacionado à classe 5 e 6 do total das ST presentes no corpus. Do outro subcorpus, obteve-se a classe 1, com 85 ST, que corresponde a 19,23\% das ST, e a classe 2, constituída de 50 ST, e que concentra 11,31\% das ST do corpus total, conforme o dendograma (Figura 2). 
Figura 2 - Dendograma das classes - Dados fornecidos pelo software Iramuteq - São Paulo, 2019.

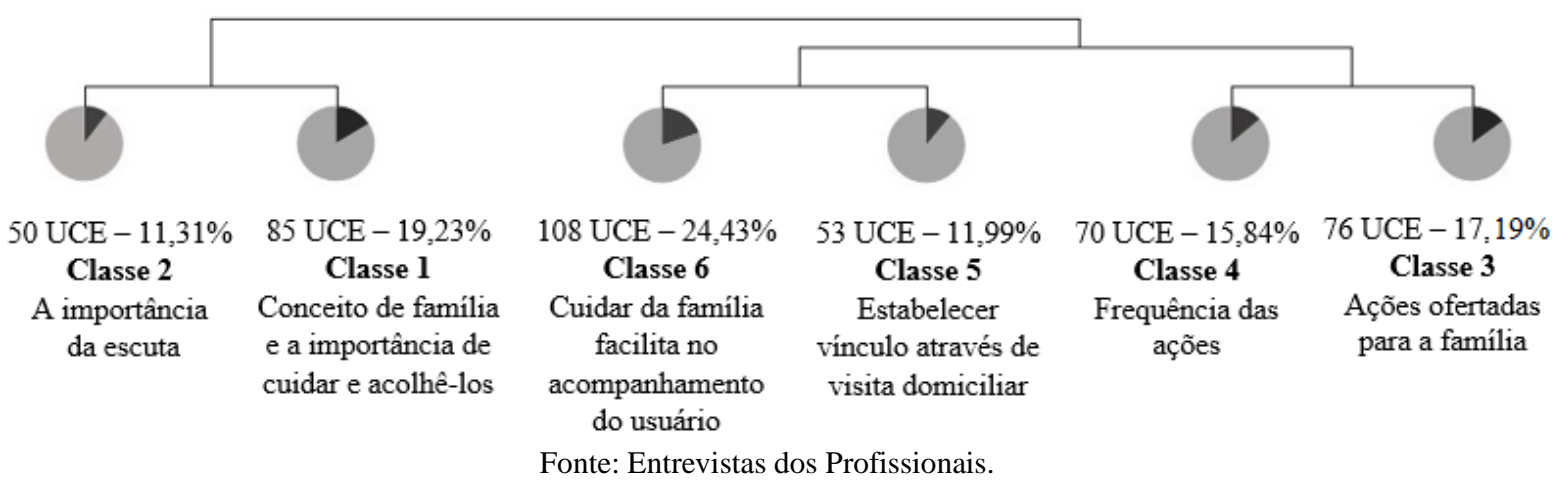

Na classe 1 - conceito de família e a importância de cuidar e acolhê-los - surgiu como definição do conceito de família o agrupamento de pessoas que se cuidam e se apoiam, independente de laços consanguíneos. Família é a base e a rede de apoio na vida do indivíduo, conforme retratam as seguintes falas:

Vai para além da questão sanguínea, como diz em genética. É pensar a família como uma rede de apoio de pessoas que se pode contar $(\mathrm{P} 1)$.

A família é um agrupamento de pessoas que constitui uma identidade entre si, seja essa identidade sanguínea ou de laços afetivos (P18).

Família são as pessoas mais próximas e com quem a gente realmente pode contar em tempo integral. Acho que até independente de sangue $(\mathrm{P} 2)$.

Em relação à importância de cuidar e acolher o familiar do usuário, emergiu a necessidade de olhar para a dinâmica familiar, considerando que esta última também adoece e o quanto esse cuidado impacta de maneira positiva no tratamento da pessoa em sofrimento mental. Além de colocar o grupo de família como espaço potente de cuidado para os familiares:

Acredito que cuidar do familiar é algo importante. Não sei se cuidar e acolher a família dentro do CAPS em todos os casos é necessário. A gente precisa qualificar esse cuidado, entender o que pode ser bom, o que o serviço pode oferecer de benéfico para a família e para a relação dela com o usuário (P7).

Esse tempo e essa abertura que a gente dá para acolher a família é importante. Essa é a parte que eu mais conheço aqui e tem o grupo de família que é um espaço aberto à noite que eu acho um espaço válido para acolher a família (P25).

A classe 2 - importância da escuta - corroborou a necessidade de ofertar escuta qualificada para a família como forma de cuidado, tendo o grupo de família como espaço de acolhida, observados nos seguintes ST:

Acho que cuidar do familiar é qualquer espaço ou intervenção que você possa fazer no sentido de fazer com que essa pessoa se sinta ouvida (P6). 
A partir do momento que você escuta, pensa formas de caminhos, de estratégias para tirar a pessoa daquela situação de angústia. Vejo que é uma ação quando eu consigo escutar o outro (P16).

Dentre os entrevistados, 18 (64,2\%) profissionais trouxeram a escuta como ação ofertada para o cuidado da família: 12 (43\%) profissionais de enfermagem, 4 (14,2\%) psicólogos, 1 (3,5\%) terapeuta ocupacional e 1 (3,5\%) médico. Os outros 10 $(35,8 \%)$ profissionais não referiram a escuta como forma de cuidado à família, relataram as ações sistematizadas como o grupo de família, atendimento nuclear e visita domiciliar.

Na classe 3 - ações promovidas pelo CAPS versus ações ofertadas pelos profissionais - respectivamente explicitou-se o grupo de família como ação específica e sistematizada, o atendimento nuclear, o atendimento individual, as visitas domiciliares, conselho gestor e os espaços de confraternização. Sobre as ações que os profissionais desenvolvem, prevaleceu o grupo de família, as visitas domiciliares e os atendimentos nucleares, conforme ilustram os excertos a seguir:

Hoje no CAPS tem o grupo de família, os atendimentos nucleares pontuais, as visitas domiciliares e ações no território. Tem o conselho gestor como espaço que o familiar também participa (P28).

Faço visita domiciliar, o atendimento telefônico que eles ligam bastante e os atendimentos familiares (P22).

A classe 4 - frequência das ações ofertadas - demonstrou que a frequência das ações de atendimentos e visitas domiciliares dependem da demanda.

Vai de acordo com a demanda. Talvez seria bom ter uma frequência para não perder esse vínculo, mas provavelmente a gente vai mais de acordo com a necessidade do caso, talvez mais na crise (P20).

Quando a situação está um pouco mais aguda ou quando há uma demanda tanto do usuário quanto da própria família, a gente avalia se é hora de fazer esse atendimento ou se a gente mantém a pessoa com a indicação para o grupo de família (P8).

A classe 5 - vínculo - enfatizou ser preciso realizar visita domiciliar para entender a dinâmica familiar e estabelecer vínculo entre o profissional de saúde e a família. Além da disponibilidade do profissional para os atendimentos telefônicos no CAPS:

Quando a gente vê que é necessário fazer a intervenção na casa ou o usuário não está vindo no CAPS, a família está ligando, falando das suas angústias e aí a gente acaba indo no domicílio para ver como está a situação (P22).

A prontidão de atendimento por telefone. Não é incomum o familiar ligar pedindo, relatando alguma situação complicada com alguém em casa e a gente fornecer orientações, acolhe e escuta. Isso faz diferença (P5).

A classe 6 - cuidar da família auxilia no acompanhamento do usuário - destacou que o vínculo do serviço com o familiar implica facilitação do manejo no tratamento do usuário, observados nos seguintes ST:

Às vezes até no manejo, no cotidiano com o usuário, fica mais fácil quando tem essa relação mais próxima com os familiares. Eu acho que o grupo de família propicia bastante isso (P5). 
A partir do grupo de família pode gerar outras ações. O familiar fala que o filho não está vindo há tempos, aí eu vou e tento ficar próximo quando ele vem no CAPS (P16).

\section{Discussão}

No que se refere ao conceito de família, a importância do cuidado e suas relações com as classes obtidas na análise textual, os participantes tem-se por definição de família: a representação de um conjunto de pessoas constituídas por relações afetivas, podendo ou não existir laços de consanguinidade entre seus membros. Além de poder propiciar a sensação de proteção, apoio e amparo entre eles, convergindo com o conceito sobre família (Mioto, 1998) adotado como base teórica no presente estudo.

A importância do cuidado e acolhimento dos familiares relaciona-se com as classes 1 e 2, que trazem a necessidade de olhar e entender a dinâmica familiar, levando em consideração as sobrecargas objetivas (cuidado diário, gastos e afazeres domésticos) e subjetivas (sentimentos) vivenciadas por aqueles que cuidam e o consequente impacto no manejo com o usuário (Reis et al, 2016). Dessa forma, percebe-se que a sobrecarga familiar é o fator que impacta diretamente nos espaços de trocas sociais e interpessoais, bem como nas experiências vivenciadas pelo binômio pessoa em sofrimento mental e família. Não se pode esquecer que o espaço de trocas do usuário é potencializado pela rede familiar, ou seja, investir no cuidado do familiar beneficia na reabilitação psicossocial e no tratamento do sujeito.

A escuta qualificada é enfatizada como importante forma de cuidar e acolher o familiar do usuário, pois propicia a formação de vínculo com o serviço e pode ser feita por todos os profissionais (Pegoraro \& Bastos, 2017). Neste estudo, houve um predomínio dessa ação por parte dos profissionais de enfermagem, que entendem a importância de ofertar escuta atenta para a família, na ambiência do CAPS ou por atendimento telefônico, como forma de fortalecer vínculo, fornecer orientação e amenizar as angústias dos familiares. Esse recurso, parte do relacionamento terapêutico, é fundamental para o acolhimento da família, além de ser uma conquista para a enfermagem nesse novo modelo de atenção psicossocial e que converge com o que é preconizado no SUS quando se trata de atendimento às famílias.

A escuta e os atendimentos telefônicos são os recursos mais utilizados pelos profissionais do CAPS, mais especificamente dos profissionais de enfermagem, conforme descritos nas Classes 2 e 3, por conta da relação mais próxima com o usuário e a família, o comprometimento com o cuidado integral e a limitação da carga horária expressa pelos profissionais de enfermagem, principalmente os que atuam em plantões noturnos. A literatura indica que tais ações vão ao encontro com o desenvolvimento da técnica do relacionamento terapêutico enfermeiro-usuário-familiares, mas são restritas pela distância na disposição das classes e pelo fato dos atendimentos telefônicos não terem acesso ao não verbal do indivíduo (Carvalho et al, 2016; Andrade \& Siqueira, 2018).

As Classes 1 e 3 demonstram, pelo distanciamento, a necessidade de se ampliar as estratégias de cuidado para além do grupo de família ou em situações de crise. Demonstram, ainda, que o cuidado e apoio prestado aos familiares é um desafio, pois apesar de se ofertar ações terapêuticas e de acolhimento para a família, estas em sua maioria não são ações sistematizadas. Isso é confirmado na Classe 3, que traz o grupo de família como única ação regular no serviço, observação essa que converge com a literatura nacional (Delgado, 2014).

As ações promovidas no CAPS e pelos profissionais de saúde em geral, além da frequência destas, relacionam-se aos resultados das Classes 3 e 4. Os profissionais relataram várias ações disponíveis no serviço, como o atendimento nuclear, o atendimento individual, as visitas domiciliares, o conselho gestor, as confraternizações e o grupo de família. Este último é uma importante ferramenta de aproximação com o serviço e de cuidado do familiar. O grupo é uma atividade com frequência semanal, aberto a todos os familiares de usuários do serviço de saúde. De acordo com estudo recente, o grupo de famĩlia é um 
espaço potente que possibilita trocas de experiências, vivências e conhecimentos, além de apoio entre as famílias (Santos, Junior \& Miranda, 2018).

As classes obtidas na análise relacionam que o cuidar da família está necessariamente vinculado ao grupo de família. No entanto, este recurso não pode ser utilizado como única opção de acolhida e escuta qualificada direcionada aos familiares, pois há outras possibilidades como: a construção de espaços coletivos de fala para os familiares, as visitas domiciliares, visitas conjuntas com profissionais da atenção básica de saúde, entre outras, a fim de potencializar o cuidado longitudinal e integral. Entende-se que as visitas devem ter frequência rotineira, organizadas de forma sistemática e não só quando surge a demanda por parte do familiar ou na crise do usuário, como é destacado pelos participantes desse estudo. Acrescenta-se, também, as atividades comemorativas que o CAPS oferece, a exemplo da festa junina e comemorações de fim de ano, que são eventos capazes de promover melhor integração e vinculação da família-usuário-equipe. Entende-se que investir em atendimentos individuais e na criação de espaço para acolher o familiar em suas necessidades, independentemente, das questões do usuário são fundamentais para o cuidado da família, o que é evidenciado na literatura consultada (Vanzela \& Pegararo, 2018).

Nos discursos dos participantes, referentes à Classe 4 , as ações ofertadas para a família variam conforme a demanda. A única ação regular que surgiu no ST foi o grupo de família. É importante ressaltar que dos 28 profissionais entrevistados, apenas 4 participavam ativamente do grupo de família. Dessa forma, fica evidente o quanto é preciso investir no fortalecimento dos espaços que já existem no serviço, a fim de sistematizar outras ações, como as visitas domiciliares e os atendimentos individuais, não só utilizar destes recursos nos momentos agudos de crise. É preciso pensar na criação de novos espaços com ações de educação em saúde, voltadas para orientação adequada sobre o processo saúde-doença, medicamento, serviços e espaços de cuidado e lazer disponíveis no território do sujeito, além da construção de estratégia conjunta com os familiares para a lida no domicílio, formas de manejo levando em consideração o contexto de vida real e os recursos que possuem (Delgado, 2014; Constantinidis \& Andrade, 2015).

O vínculo do serviço de saúde com as famílias está atrelado à visita domiciliar, de acordo com a Classe 5. A visita domiciliar, vista como potencialidade para o cuidado, possibilita conhecer a dinâmica familiar, fortalecer o vínculo com a equipe, elaborar estratégias e planos de cuidado no contexto de vida em que o núcleo familiar está inserido, levando em consideração, suas necessidades. Sendo assim, as ações pensadas nas visitas domiciliares ajudarão no acolhimento, escuta, cuidado integral e orientação aos familiares, a fim de diminuir as crises e as internações do usuário, auxiliar no manejo deste e melhorar a qualidade de vida no domicílio (Santos \& Carmo, 2015; Morais, Guimarães, Alves, \& Monteiro, 2021).

A proximidade das Classes 4 e 5, apesar da semelhança na ação de visita domiciliar, revela uma fragilização em relação à frequência desta ação. Pois, o vínculo, fortalecido e estabelecido através de visitas domiciliares pode não ocorrer ou se enfraquecer quando esta ação, não sistematizada, ocorre em sua maioria nos períodos de crise.

O cuidado com a família e o vínculo desta com a equipe, evidenciado na Classe 6 facilitou no acompanhamento do usuário. A família, coparticipante no cuidado, exerce um papel importante no tratamento do sujeito com sofrimento mental, pois ao ser apoiada e orientada pela equipe de saúde, atuará em conjunto para auxiliar na inclusão social do usuário.

O vínculo com os profissionais de saúde é estabelecido a partir da escuta atenta, principalmente em ação de visita domiciliar, quando a família se sente acolhida e é orientada adequadamente em suas reais necessidades. Este cuidado com o familiar é ampliado no grupo de família, espaço potente de trocas e apoio, além dos atendimentos individuais, nucleares ou a participação no conselho gestor e confraternizações. Ressalta-se que a efetividade dessas ações está atrelada a sua frequência. Sendo assim, ao acolher o familiar, haverá o fortalecimento do vínculo, promoção de autonomia do usuário, diminuição dos conflitos relacionais e melhora na qualidade de vida no domicílio (Figueiro \& Dimenstein, 2020).

Ambas as técnicas, utilizadas para analisar o corpus gerado pela entrevista dos profissionais, demonstram que as ações realizadas pelos profissionais de saúde destacaram a escuta como base para a compreensão das necessidades tanto da família 
quanto dos usuários, necessidades dos usuários estas que chegam, muitas vezes, após o entendimento da dinâmica familiar. As ações mais citadas são a visita domiciliar e o grupo de família, momentos esses que o cuidado ao familiar é posto em prática e o vínculo entre profissional e família é estabelecido. Porém, a fragilidade dessas ações do processo de cuidado à família se dá de acordo com a demanda dos sujeitos envolvidos sendo descontinuada após solucionar a crise, o que diverge das portarias e da própria política pública de saúde mental, isto é, do SUS.

Limitações do estudo: 1) a delimitação geográfica que traduz a realidade de um município em específico e 2) o fato do cenário do estudo se restringir a um único CAPSIII.

\section{Considerações Finais}

Esta pesquisa permitiu identificar as ações dos profissionais de saúde acerca do cuidado prestado aos familiares de usuários de um CAPS adulto III. Conforme o referencial adotado, na reabilitação psicossocial, tem-se a aproximação da família como parceira no tratamento do usuário. Esta pelo fato de conviver com as sobrecargas em decorrência do sofrimento mental do sujeito os trabalhadores entendem que também precisa ser acolhida e amparada.

As ações disponíveis no serviço em relação a família são: grupo de família, visita domiciliar, atendimento nuclear e individual. Destas, o grupo de família apareceu como único recurso sistematizado e regular e não são todos os trabalhadores que se apropriam deste espaço.

Em relação aos outros dispositivos de cuidado, evidenciou-se a visita domiciliar como essencial para formação de vínculo e aproximação da família com a equipe, porém não é uma atividade regular. As visitas são realizadas conforme surgem as demandas que em sua maioria são nos períodos de crise dos usuários.

Os resultados deste estudo mostram a necessidade de ampliar ações de cuidado e pesquisas em relação a família na atenção psicossocial para se avançar nas políticas públicas e consolidar a Reforma Psiquiátrica brasileira. Nesse sentido, os estudos futuros sobre nessa temática, poderão desvelar como as ações de cuidado à família impactam nas políticas de saúde mental das famílias.

\section{Referências}

Andrade, J. N. B., \& Siqueira, F. M. (2018) A atuação do enfermeiro nos Centros de Atenção Psicossocial. Rev Enferm UFJF [Internet], 4(1):83-92. https://periodicos.ufjf.br/index.php/enfermagem/article/view/14020

Carvalho, P. A. L., Moura, M. S., Carvalho, V. T., Reis, M. C. S., Lima, C. B. O., \& Sena, E. L. S. (2016). The family in the psychosocial rehabilitation of people with mental suffering. J Nurs UFPE on line, 10(5):1071-8. 10.5205/reuol.9003-78704-1-SM.1005201616

Constantinidis, T. C., \& Andrade, A. N. (2015). Demanda e oferta no encontro entre profissionais de saúde mental e familiares de pessoas com sofrimento psíquico. Cien Saúde Colet, 20(2):333-342. 10.1590/1413-81232015202.18652013

Delgado, P. G. (2014). Sobrecarga do cuidado, solidariedade e estratégia de lida na experiência de familiares de Centros de Atenção Psicossocial. Physis, 24(4):1103-1126. http://dx.doi.org/10.1590/S0103-73312014000400007

Figueiro, M., \& Dimenstein, M. (2020). Rede de saúde mental e acolhimento para as famílias que sofrem com problemas decorrentes do uso de drogas no município do Natal, Rio Grande do Norte. Psicología, Conocimiento y Sociedad, 10(1), 81-100. 10.26864/PCS.v10.n1.4

Gomes, T. B., \& Santos, J. B. F. (2016). Dilemas e vicissitudes de famílias em situação de vulnerabilidade social no contexto da desinstitucionalização psiquiátrica. Physis, 26(1):271-287. http://dx.doi.org/10.1590/S0103-73312016000100015

Lima, M. S., Aguiar, A. C. L, \& Sousa, M. M. (2015). The shared care in mental health as potential of user autonomy. Psicol Estud, 20(4):675-686. 10.4025/psicolestud.v20i4.28309

Lowen, I. M. V., Peres, A. M., Crozeta, K., Bernardino, E., \& Beck, C. L. C. (2015). Managerial Nursing competencies in the expansion of the Family Health Strategy*. Rev Esc Enferm USP, 49(6):967-973. 10.1590/S0080-623420150000600013

Minayo, M. C. S. (2010) O desafio do conhecimento: pesquisa qualitativa em saúde. (12a ed.), Hucitec.

Estrela, C. (2018). Metodologia Científica: Ciência, Ensino, Pesquisa. Editora Artes Médicas. 
Research, Society and Development, v. 10, n. 11, e153101119365, 2021

(CC BY 4.0) | ISSN 2525-3409 | DOI: http://dx.doi.org/10.33448/rsd-v10i11.19365

Jafelice, G. T., Ziliotto, G. C., \& Marcolan, J. F. (2020). Conception of the professionals of psychosocial care center on public policies of mental health. Research, Society and Development, 9(5), e71953100. https://doi.org/10.33448/rsd-v9i5.3100

Mioto, R. C. T. (1998). Família e saúde mental: contribuições para reflexão sobre processos familiares. Rev Katálysis [Internet], 0(2): 20-26. https://periodicos.ufsc.br/index.php/katalysis/article/view/5573/4974

Morais, A. P. P., Guimarães, J. M. X., Alves, L. V. C., \& Monteiro, A. R. M. (2021). Produção do cuidado na atenção psicossocial: visita domiciliar como tecnologia de intervenção no território. Ciência \& Saúde Coletiva, 26, 1163-1172. 10.1590/1413-81232021263.09102019

Oliveira, K. K. D., Rangel, C. T., Maia, C. A. A. S., Júnior, J. M. P., Fernandes, R. L., \& Miranda, F. A. N. (2016). Contextual aspects of family participation in psychosocial care centers. J Nurs UFPE on line, 10(4):3676-81. 10.5205/reuol.9681-89824-1-ED.1004sup201620

Pegoraro, R. F., \& Bastos, L. S. N. (2017). Experiences of embracement according to professionals of a psychosocial attention center. Rev Enferm Atenção Saúde [Internet], 6(1):3-17. http://seer.uftm.edu.br/revistaeletronica/index.php/enfer/article/view/1525/pdf_1

Randemark, N. F. R., \& Barros, S. (2014). The family in therapeutic design of users of CAPS: Representations of health professionals. J Nurs UFPE on line, 8(7):1956-64. 10.5205/reuol.5963-51246-1-RV.0807201417

Reis, T. L., Dahl, C. M., Barbosa, S. M., Teixeira, M. R., \& Delgado, P. G. G. (2016). Burden and participation of family in the care of Psychosocial Care Centers users. Saúde Debate, 40(109):70-85. 10.1590/0103-1104201610906

Santos, C. D., \& Carmo, D. R. Estratégias de inserção familiar no CAPS. Rev Uningá [Internet], 43:81-85. http://revista.uninga.br/index.php/uninga/arti cle/view/1205/827

Santos, R. C. A., Junior, J. M. P., \& Miranda, F. A. N. (2018) Psychosocial care network: adequacy of roles and functions performed by professionals. Rev Gaúcha Enferm, 39:e57448. http://dx.doi.org/10.1590/1983-1447.2018.57448

Saraceno, B. (2001). Libertando identidades: da reabilitação psicossocial à cidadania possível. (2a ed.), Te Corá/Instituto Franco Basaglia.

Souza, M. A. R., Wall, M. L., Thuler, A. C. M. C., Lowen, I. M. V., \& Peres, A. M. (2018). The use of IRAMUTEQ software for data analysis in qualitative research. Rev Esc Enferm USP, 52:e03353. http://dx.doi.org/10.1590/S1980-220X2017015003353

Vanzela, C. B., \& Pegararo, R, F. (2018) Avaliação de Centros de Atenção Psicossocial segundo familiares: revisão integrativa de literatura. Rev Psicol Saúde, 10(2):53-66. http://dx.doi.org/10.20435/pssa.v10i2.622 